\title{
Influence of mechanical milling and thermal annealing on electrical and magnetic properties of nanostructured $\mathrm{Ni}-\mathrm{Zn}$ and cobalt ferrites
}

\author{
A NARAYANASAMY* and N SIVAKUMAR \\ Materials Science Centre, Department of Nuclear Physics, University of Madras, Guindy Campus, \\ Chennai 600 025, India
}

\begin{abstract}
The present article reports some of the interesting and important electrical and magnetic properties of nanostructured spinel ferrites such as $\mathrm{Ni}_{0.5} \mathrm{Zn}_{0.5} \mathrm{Fe}_{2} \mathrm{O}_{4}$ and $\mathrm{CoFe}_{2} \mathrm{O}_{4}$. In the case of $\mathrm{Ni}_{0.5} \mathrm{Zn}_{0.5} \mathrm{Fe}_{2} \mathrm{O}_{4}$, d.c. electrical conductivity increases upon milling, and it is attributed to oxygen vacancies created by high energy mechanical milling. The real part of dielectric constant $\left(\varepsilon^{\prime}\right)$ for the milled sample is found to be about an order of magnitude smaller than that of the bulk nickel zinc ferrite. The increase in Néel temperature from $538 \mathrm{~K}$ in the bulk state to $611 \mathrm{~K}$ on the reduction of grain size upon milling has been explained based on the change in the cation distribution. The dielectric constant is smaller by an order of magnitude and the dielectric loss is three orders of magnitude smaller for the milled sample compared to that of the bulk. In the case of cobalt ferrite, the observed decrease in conductivity, when the grain size is increased from 8-92 $\mathbf{~ m m}$ upon thermal annealing is clearly due to the predominant effect of migration of some of the $\mathrm{Fe}^{3+}$ ions from octahedral to tetrahedral sites, as is evident from in-field Mössbauer and EXAFS measurements. The dielectric loss $(\tan \delta)$ is an order of magnitude smaller for the nano sized particles compared to that of the bulk counterpart.
\end{abstract}

Keywords. Nanocrystalline cobalt and nickel zinc ferrite; electrical properties; Mössbauer; EXAFS.

\section{Introduction}

Nanocrystalline spinel ferrite materials are of practical interest in a wide range of applications like high-density information storage, magnetic resonance imaging, targeted drug delivery, etc (Bulte et al 1999; Lübbe et al 1999). Spinel ferrites have high electrical resistivities and low eddy current and dielectric losses and therefore, they are found to be very useful in technological applications (Igarash and Okazaki 1977; Kulikowski 1984). In this article, we report the details of synthesis and electrical and magnetic properties of $\mathrm{Ni}_{0.5} \mathrm{Zn}_{0.5} \mathrm{Fe}_{2} \mathrm{O}_{4}$ and $\mathrm{CoFe}_{2} \mathrm{O}_{4}$.

\section{Experimental}

The $\mathrm{Ni}_{0.5} \mathrm{Zn}_{0.5} \mathrm{Fe}_{2} \mathrm{O}_{4}$ and $\mathrm{CoFe}_{2} \mathrm{O}_{4}$ ferrites were synthesized using the ceramic and co-precipitation route, respectively. In the case of $\mathrm{Ni}-\mathrm{Zn}$ ferrite, the powders of $\alpha-\mathrm{Fe}_{2} \mathrm{O}_{3}, \mathrm{NiO}$ and $\mathrm{ZnO}$ in the required stoichiometry were thoroughly mixed in a high energy ball mill using zirconia balls and vials with a speed of $300 \mathrm{rpm}$. The mixture was presintered at $1173 \mathrm{~K}$ for $5 \mathrm{~h}$ in air, which was then furnace-cooled to room temperature. The cold ferrite powder was ground in an agate mortar and pelletized. The pellets were then sintered at $1473 \mathrm{~K}$ for $5 \mathrm{~h}$ in air and furnace-cooled. The pellets were reduced to powders by milling using zirconia

*Author for correspondence (ansjourn@rediffmail.com) vials and balls at $300 \mathrm{rpm}$ for $30 \mathrm{~min}$ and taken to be the as-prepared sample. The as-prepared sample was milled up to $25 \mathrm{~h}$ using planetary high-energy ball mill (Fritsch pulverisette 7) with zirconia vials and balls. The milling speed was $600 \mathrm{rpm}$ with a ball to powder weight ratio of $8: 1$. The crystallographic phase analysis for the as-prepared and milled samples was carried out using X-ray diffraction (XRD) with a Rigaku-make high precision Guinier $\mathrm{X}$-ray diffractometer and $\mathrm{Cu}-\mathrm{K} \alpha$ radiation. The Néel temperature was determined using thermogravimetric analyser (Perkin-Elmer series 7) by applying a small magnetic field of $4 \mathrm{mT}$ using a horse-shoe magnet. Magnetization studies were carried out at $298 \mathrm{~K}$ by using a vibrating sample magnetometer (VSM, EG\&G, PARC, Model 4500, USA) with a maximum available field of $0.7 \mathrm{~T}$. The extended X-ray absorption fine structure (EXAFS) measurements were done using a laboratory X-ray absorption spectrometer (Rigaku R-XAS Lopper) at Ni K (8332 eV) and Zn K (9663 eV) absorption edges. The $\mathrm{CoFe}_{2} \mathrm{O}_{4}$ ferrite was prepared using the conventional co-precipitation route. In the conventional co-precipitation technique, $800 \mathrm{ml}$ of mixed $0 \cdot 11-\mathrm{M} \mathrm{Fe}$ and $0 \cdot 055-\mathrm{FeCo}$ solution was added into the reaction vessel containing 1.51 of boiling $0.725 \mathrm{M} \mathrm{NaOH}$ aqueous solution under mechanical stirring at $500 \mathrm{rpm}$. The ferrite formation was monitored by sampling the suspension during the contact period. The ${ }^{57} \mathrm{Fe}$ Mössbauer spectra were recorded at $15 \mathrm{~K}$ with $8 \mathrm{~T}$ magnetic field applied parallel to the direction of gamma rays. For both $\mathrm{Ni}_{0.5} \mathrm{Zn}_{0.5} \mathrm{Fe}_{2} \mathrm{O}_{4}$ and $\mathrm{CoFe}_{2} \mathrm{O}_{4}$, 
the electrical conductivity and dielectric measurements were carried out as a function of both frequency and temperature in the range $1 \mathrm{~Hz}-10 \mathrm{MHz}$ and $300-823 \mathrm{~K}$, respectively using an impedance/gain phase analyser (Solartron 1260) with a personal computer and software to acquire the impedance data.

\section{Results and discussion}

\section{$3.1 \mathrm{Ni}_{0.5} \mathrm{Zn}_{0.5} \mathrm{Fe}_{2} \mathrm{O}_{4}$}

3.1a Phase analysis: Figure 1 shows the XRD patterns of the $\mathrm{Ni}-\mathrm{Zn}$ ferrite for the as-prepared and $25 \mathrm{~h}$ milled sample. The peaks could be indexed to a single phase spinel ferrite. The grain size was calculated from the fullwidth at half-maximum of the (311) peak using Scherrer's formula. The grain size of the as-prepared and $25 \mathrm{~h}$ milled samples were 50 and $14 \mathrm{~nm}$, respectively.

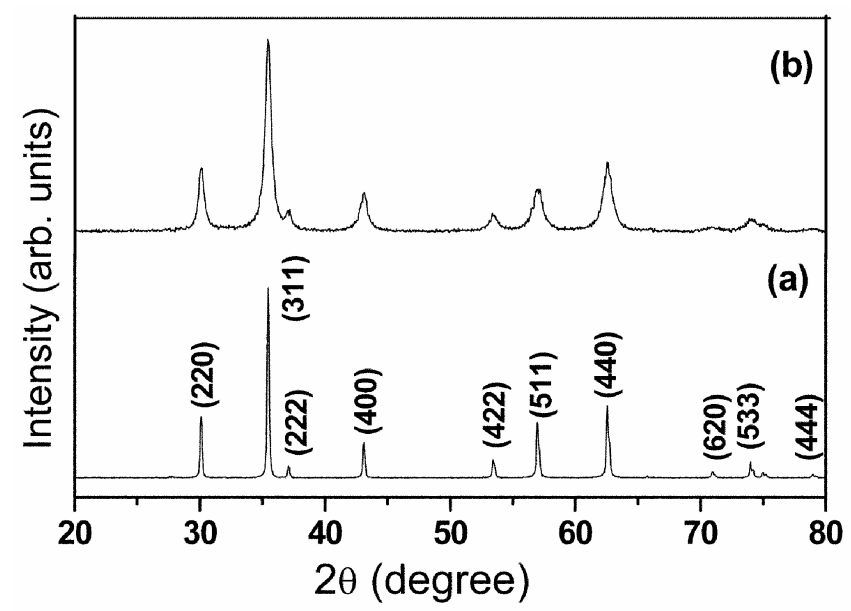

Figure 1. The XRD patterns of $\mathrm{Ni}_{0.5} \mathrm{Zn}_{0.5} \mathrm{Fe}_{2} \mathrm{O}_{4}$ spinel samples: (a) as-prepared and (b) $25 \mathrm{~h}$ milled sample.



Figure 2. The thermogravimetric plots for the $\mathrm{Ni}_{0.5} \mathrm{Zn}_{0.5} \mathrm{Fe}_{2} \mathrm{O}_{4}$ : (a) as-prepared (50 nm) and (b) $25 \mathrm{~h}$ milled (14 nm) samples. 3.1b Néel temperature measurements: Thermogravimetric plots of $\mathrm{Ni}_{0.5} \mathrm{Zn}_{0.5} \mathrm{Fe}_{2} \mathrm{O}_{4}$ obtained with a small magnetic applied field of $4 \mathrm{mT}$ are shown in figure 2 for as-prepared and $25 \mathrm{~h}$ milled samples. The Néel temperature is found to increase from $573 \mathrm{~K}$ for the as-prepared sample to $611 \mathrm{~K}$ for the $25 \mathrm{~h}$ milled sample. The rise in Néel temperature for the smaller grain size is due to the increase in the strength of $A-B$ superexchange interaction as a result of increase in the population of $\mathrm{Fe}^{3+}$ ions in $A$ site upon milling as confirmed by our in-field Mössbauer study (Sivakumar et al 2006).

3.1c Magnetization studies: Figure 3 shows the $M-H$ loops obtained using VSM for the as-prepared and $25 \mathrm{~h}$ milled sample. The magnetization of the as-prepared sample is $72 \mathrm{emu} / \mathrm{g}$ which is almost equal to that of the bulk sample (micron size particle: $73 \mathrm{emu} / \mathrm{g}$ ) (Smit and Wijn 1959). For the $25 \mathrm{~h}$ milled sample, magnetization decreases by about $15 \%$ to $61 \mathrm{emu} / \mathrm{g}$ due to the migration of some of the $\mathrm{Fe}^{3+}$ ions from $\mathrm{B}$ to $\mathrm{A}$ sites and $\mathrm{Zn}^{2+}$ ions from A to B sites upon milling (Sivakumar et al 2006). The coercivity increases from 88 Oe for the as-prepared sample to 349 Oe for the $25 \mathrm{~h}$ milled sample and it is due to both the surface anisotropy of the small particles and the strain induced in the sample during milling.

3.1d Extended X-ray absorption fine structure analysis (EXAFS): We have carried out EXAFS measurements to study the local atomic environment around the absorption atom and to study the changes in the cation distribution in the nanostructured $\mathrm{Ni}_{0.5} \mathrm{Zn}_{0.5} \mathrm{Fe}_{2} \mathrm{O}_{4}$ upon milling. Figures 4(a) and (b) show the Fourier-transformed EXAFS spectra at $\mathrm{Zn}$ and $\mathrm{Ni}-\mathrm{K}$ edge, respectively, for both asprepared and $25 \mathrm{~h}$ milled samples. From figure 4(a), it can easily be understood that the atomic environment



Figure 3. The $\mathrm{M}-\mathrm{H}$ loops of $\mathrm{Ni}_{0.5} \mathrm{Zn}_{0.5} \mathrm{Fe}_{2} \mathrm{O}_{4}$ at $300 \mathrm{~K}$ for the (a) as-prepared and (b) $25 \mathrm{~h}$ milled sample (14 nm). 

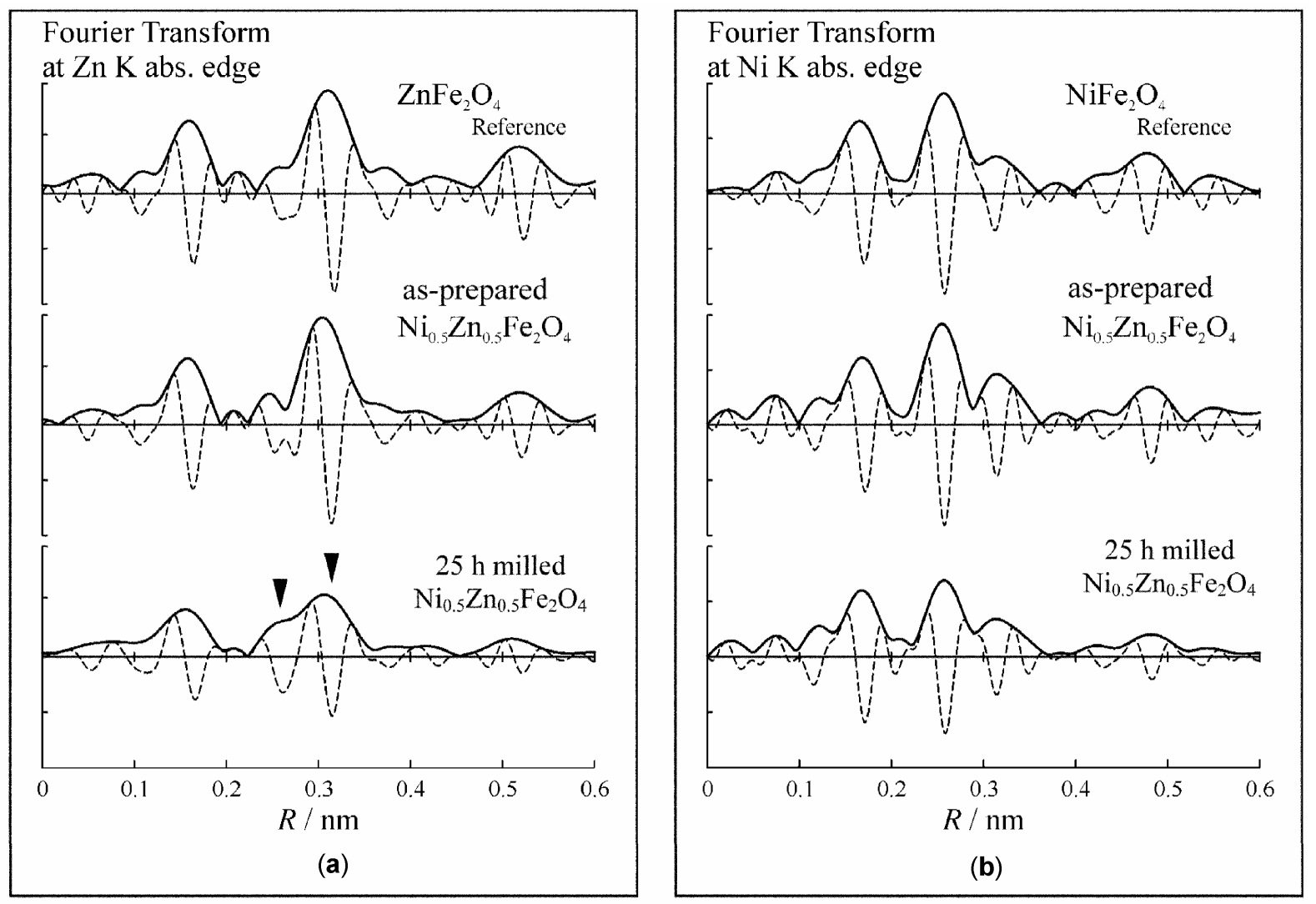

Figure 4. (a) Fourier transforms of EXAFS spectra at $\mathrm{Zn} \mathrm{K}$ absorption edge of $\mathrm{Ni}_{0.5} \mathrm{Zn}_{0.5} \mathrm{Fe}_{2} \mathrm{O}_{4}$ ferrite samples and $\mathrm{ZnFe}_{2} \mathrm{O}_{4}$ reference and (b) at $\mathrm{Ni} \mathrm{K}$ absorption edge of $\mathrm{Ni}_{0.5} \mathrm{Zn}_{0.5} \mathrm{Fe}_{2} \mathrm{O}_{4}$ ferrite samples and $\mathrm{NiFe}_{2} \mathrm{O}_{4}$ reference.

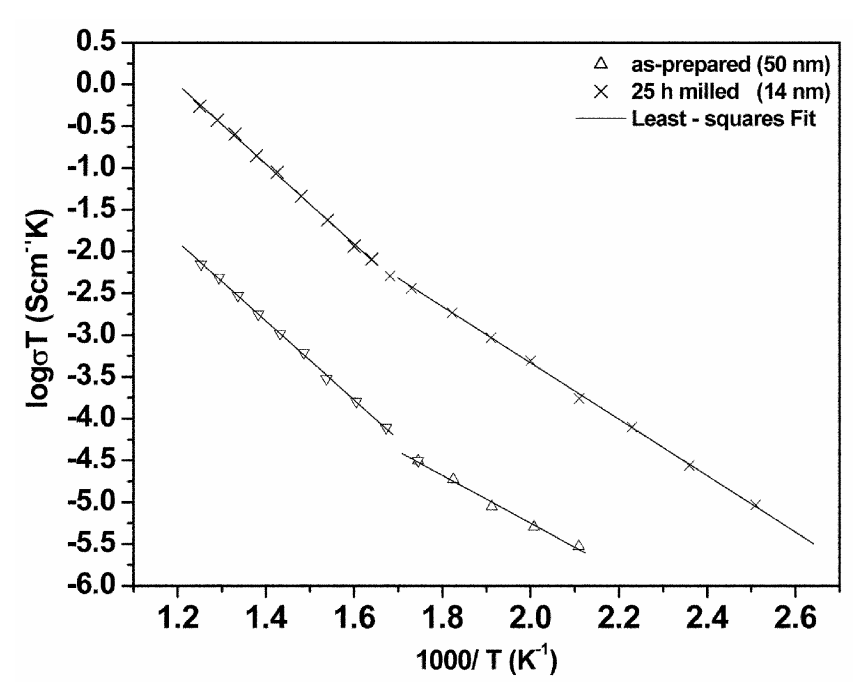

Figure 5. Arrhenius plots for electrical conductivity of the asprepared and $25 \mathrm{~h}$ milled $\mathrm{Ni}_{0.5} \mathrm{Zn}_{0.5} \mathrm{Fe}_{2} \mathrm{O}_{4}$ samples. The solid lines are the linear fit to the experimental data.

around $\mathrm{Zn}^{2+}$ ion in the as-prepared sample is quite similar to that in the reference sample with a strong $r$-space peak near $3 \AA$, which indicates that all $\mathrm{Zn}^{2+}$ ions occupy the tetrahedral site. For the $25 \mathrm{~h}$ milled sample, one can eas- ily observe that the atomic environment around $\mathrm{Zn}^{2+}$ ion is quite different from that in the normal structure. The new peak at $2 \cdot 6 \AA$ is due to $B-B$ correlation with a substantial intensity showing that there is a partial transfer of $\mathrm{Zn}^{2+}$ ions from $A$ to $B$ sites after milling. From figure 4(b), we find that the EXAFS spectra of the reference, asprepared and $25 \mathrm{~h}$ milled $\mathrm{Ni}_{0.5} \mathrm{Zn}_{0.5} \mathrm{Fe}_{2} \mathrm{O}_{4}$ are quite similar to each other. Hence, one can conclude that the $\mathrm{Ni}^{2+}$ ions occupy only the octahedral sites and that they do not migrate from the octahedral to the tetrahedral site upon milling.

3.1e D.C. conductivity: Figure 5 shows the Arrhenius plots for the electrical conductivity of both the asprepared and $25 \mathrm{~h}$ milled samples in the temperature range between 400 and $798 \mathrm{~K}$. The grain boundary resistance was obtained by analysing the data using the nonlinear least-squares (NLLS) fitting routine. The d.c. conductivity of the grain boundary was calculated from the resistance value and by using the geometrical dimension of the sample. The conductivity increases with temperature as expected from the semiconducting behaviour of spinel ferrites. The activation energy for the thermally activated hopping process was obtained by fitting the d.c. conductivity data with the Arrhenius relation 
Table 1. The values of activation energies and the Curie temperatures of $\mathrm{Ni}_{0.5} \mathrm{Zn}_{0.5} \mathrm{Fe}_{2} \mathrm{O}_{4}$ for the as-prepared and $25 \mathrm{~h}$ milled sample. $E_{\mathrm{a} 1}$ is the activation energy obtained from the conductivity data for the low temperature region and $E_{\mathrm{a} 2}$ is that for the hightemperature region.

\begin{tabular}{lccllll}
\hline & \multicolumn{3}{c}{ Activation energy from conductivity data } & & \multicolumn{2}{c}{$T_{\mathrm{c}}$ from } \\
\cline { 2 - 3 } Sample & $E_{\mathrm{a} 1}(\mathrm{eV})$ & $E_{\mathrm{a} 2}(\mathrm{eV})$ & & $\begin{array}{c}\text { Arrhenius } \\
\text { plot }(\mathrm{K})\end{array}$ & TGA $(\mathrm{K})$ & $\begin{array}{c}\text { Thermomagnetic } \\
\text { measurements }(\mathrm{K})\end{array}$ \\
\hline As-prepared $(50 \mathrm{~nm})$ & $0.57( \pm 0.01)$ & $0.93( \pm 0.01)$ & & $569( \pm 2)$ & $573( \pm 1)$ & $569( \pm 1)$ \\
25 h milled $(14 \mathrm{~nm})$ & $0.66( \pm 0.02)$ & $0.93( \pm 0.01)$ & & $607( \pm 3)$ & $611( \pm 1)$ & $607( \pm 1)$ \\
\hline
\end{tabular}


Figure 6. (a) Real part of the dielectric constant $\left(\varepsilon^{\prime}\right)$ at $373 \mathrm{~K}$ as a function of frequency for the as-prepared and $25 \mathrm{~h}$ milled $\mathrm{Ni}_{0.5} \mathrm{Zn}_{0.5} \mathrm{Fe}_{2} \mathrm{O}_{4}$ samples and (b) dielectric loss factor $(\tan \delta$ ) at $373 \mathrm{~K}$ as a function of frequency for as-prepared and $25 \mathrm{~h}$ milled $\mathrm{Ni}_{0.5} \mathrm{Zn}_{0.5} \mathrm{Fe}_{2} \mathrm{O}_{4}$ samples.

$$
\sigma T=\sigma_{0} \exp \left[\frac{E_{\mathrm{a}}}{K T}\right],
$$

where $\sigma_{0}$ is the pre-exponential factor with dimensions of $(\Omega \mathrm{cm})^{-1} \mathrm{~K}, E_{\mathrm{a}}$ the activation energy for d.c. conductivity and $k$ the Boltzmann constant. The values of activation energies for the as-prepared and $25 \mathrm{~h}$ milled samples are given in table 1. The change of slopes in Arrhenius plot for both as-prepared and $25 \mathrm{~h}$ milled samples corresponds to the ferromagnetic to paramagnetic transition temperatures as confirmed by the thermogravimetric measurements as shown in table 1. The conductivity is expected to decrease upon milling because of the grain size reduction and also because of the decrease in the number of $\mathrm{Fe}^{3+} \leftrightarrow \mathrm{Fe}^{2+}$ pairs in the octahedral site arising from the partial displacement of $\mathrm{Fe}^{3+}$ ions from octahedral site to tetrahedral site due to milling as evident by the in-field Mössbauer studies reported earlier (Sivakumar et al 2006). On the contrary, we have observed an increase in conductivity with the reduction of grain size upon milling. Earlier, it (Goya and Rechenberg 1999) has been observed that oxygen ions escape from the spinel structure, thereby creating anion vacancies during milling. In the present study, therefore, the increase in conductivity with the reduction of grain size can be attributed to oxygen vacancies created during high energy ball milling. In general, the activation energy for conductivity due to electron hopping in bulk $\mathrm{Ni}_{0.5} \mathrm{Zn}_{0.5} \mathrm{Fe}_{2} \mathrm{O}_{4}$ ferrites is of the order of $0.4 \mathrm{eV}$ (Abdeen 1999). In the present work, the high values $(0.57$ and $0.66 \mathrm{eV})$ of activation energies for the as-prepared and $25 \mathrm{~h}$ milled samples, respectively obtained in the low temperature region may be due to hole hopping in addition to electron hopping contributing to conduction. The anion vacancies are activated at higher activation energy $(\approx 0.93 \mathrm{eV})$, which is characteristic of diffusion of oxygen vacancies (Waster 1991).

\section{1f Dielectric behaviour: (i) Frequency dependence} of dielectric constant and dielectric loss: Figure 6(a) shows the frequency dependence of dielectric constant $\left(\varepsilon^{\prime}\right)$ for the as-prepared and $25 \mathrm{~h}$ milled samples. The dielectric constant decreases with grain size reduction upon milling. In general, the electron exchange between $\mathrm{Fe}^{2+}$ and $\mathrm{Fe}^{3+}$ ions which results in local displacement of electrons in the direction of electric field determines electric polarization in spinel ferrites. The dielectric constant of ferrites varies mainly due to the fluctuations in the concentration of $\mathrm{Fe}^{2+}$ ions (Koops 1951; Rezlescu and Rezlescu 1974; Waster 1991). The polarization and dielectric constant are expected to increase with the concentration of 
$\mathrm{Fe}^{2+}$. In the present work, for the $25 \mathrm{~h}$ milled sample, there is a migration of some of the $\mathrm{Fe}^{3+}$ ions from octahedral $(B)$ to tetrahedral $(A)$ sites, which is clearly evident from the in-field Mössbauer studies (Sivakumar et al 2006). Therefore, the dielectric constant $\left(\varepsilon^{\prime}\right)$ is lower for the $25 \mathrm{~h}$ milled $(14 \mathrm{~nm})$ sample compared to that of the as-prepared sample $(50 \mathrm{~nm})$. Verma et al (1999) obtained a value of about 100 for $\varepsilon^{\prime}$ at room temperature and at $100 \mathrm{kHz}$ for the bulk (8 $\mu \mathrm{m}$ grain size) $\mathrm{Ni}_{0.5} \mathrm{Zn}_{0.5} \mathrm{Fe}_{2} \mathrm{O}_{4}$ ferrite. In our measurements, $\varepsilon^{\prime}$ is found to be an order of magnitude smaller for the $25 \mathrm{~h}$ milled $\mathrm{Ni}_{0.5} \mathrm{Zn}_{0.5} \mathrm{Fe}_{2} \mathrm{O}_{4}$ sample at the same temperature and frequency.

In general, the dielectric constant should decrease monotonically with frequency in ferrites, because the electron exchange between $\mathrm{Fe}^{2+} \leftrightarrow \mathrm{Fe}^{3+}$ ions cannot follow the alternating electric field beyond a certain critical frequency. However, in the present sample, $\varepsilon^{\prime}$ shows anomalous behaviour with frequency for both as-prepared
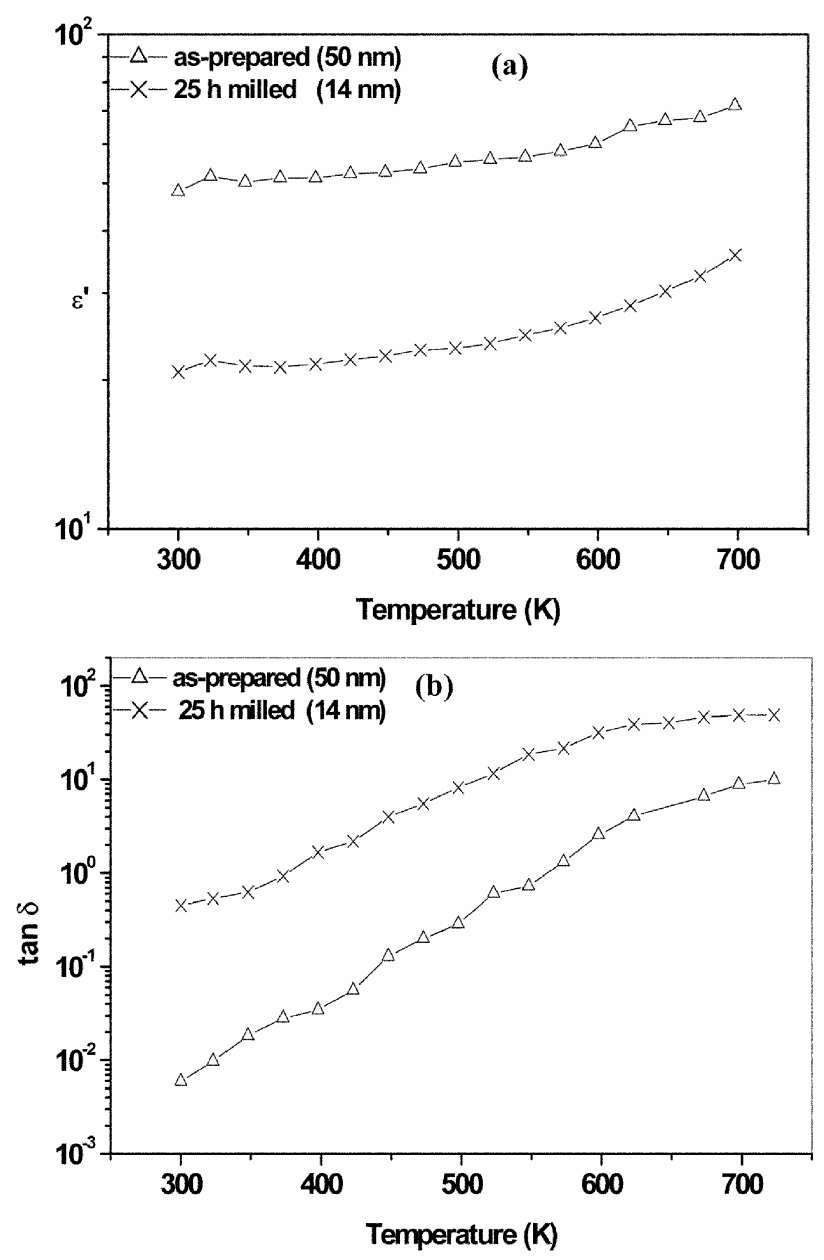

Figure 7. (a) Temperature dependence of dielectric constant $\left(\varepsilon^{\prime}\right)$ for the as-prepared and $25 \mathrm{~h}$ milled $\mathrm{Ni}_{0.5} \mathrm{Zn}_{0.5} \mathrm{Fe}_{2} \mathrm{O}_{4}$ samples at $100 \mathrm{kHz}$ and (b) temperature dependence of dielectric loss factor $(\tan \delta)$ for the as-prepared and $25 \mathrm{~h}$ milled $\mathrm{Ni}_{0.5} \mathrm{Zn}_{0.5} \mathrm{Fe}_{2} \mathrm{O}_{4}$ samples at $100 \mathrm{kHz}$. (The line joining the data points is a guide to the eye). and $25 \mathrm{~h}$ milled samples. Initially it increases with the frequency, reaches a maximum and then decreases with further increase in the frequency. The presence of $\mathrm{Ni}^{3+}$ and $\mathrm{Ni}^{2+}$ ions in $\mathrm{B}$ sites gives rise to $p$-type carriers which also contribute to the net polarization in addition to the $n$ type carriers. However, the contribution of the $p$-type carriers should be smaller than that from the $n$-type carriers with an opposite sign. Since the $p$-type carriers have a lower mobility than the $n$-type carriers, the contribution to polarization from the former will decrease more rapidly even at low frequencies than the latter. Therefore, the net contribution will increase initially and then decrease with frequency as observed in the present samples and shown in figure 6(a). Rezlescu and Rezlescu (1974) also reported a similar behaviour in the case of $\mathrm{Cu}-\mathrm{Ni}$ ferrites.

Figure 6(b) shows the plot between dielectric loss $(\tan \delta$ ) and frequency for the as-prepared and $25 \mathrm{~h}$ milled

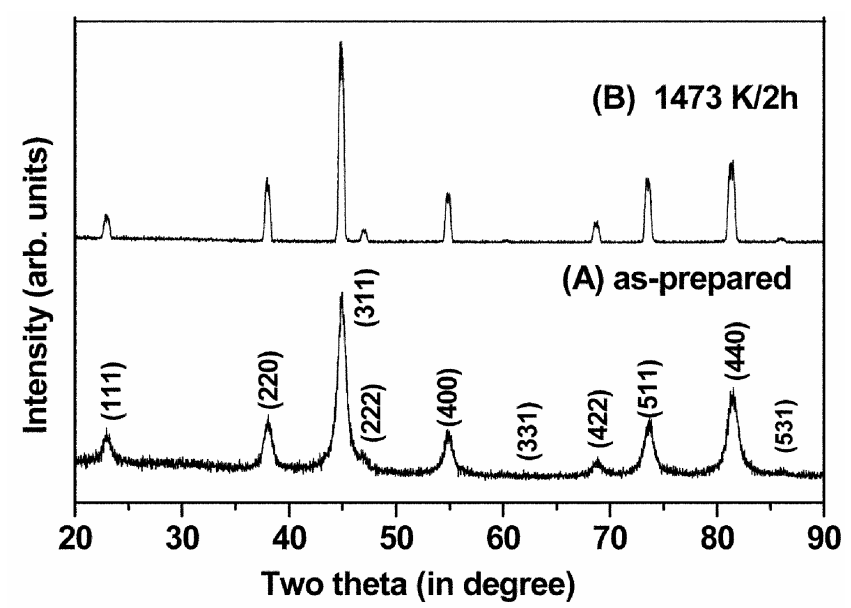

Figure 8. XRD patterns of $\mathrm{CoFe}_{2} \mathrm{O}_{4}$ spinel samples.

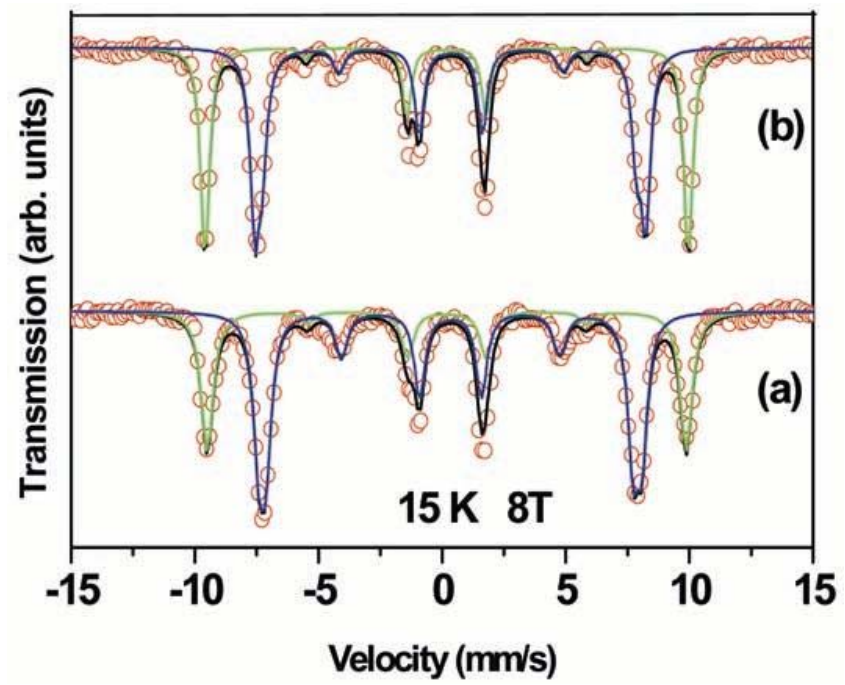

Figure 9. $8 \mathrm{~T}$ in-field Mössbauer spectra of the $\mathrm{CoFe}_{2} \mathrm{O}_{4}$ spinel ferrite for (a) as-prepared $(8 \mathrm{~nm})$ and (b) annealed at $1473 \mathrm{~K}$ for $2 \mathrm{~h}(92 \mathrm{~nm})$. 
Table 2. Mössbauer parameters: Isomer shift $\langle I S\rangle$, quadrupole shift $\langle 2 \varepsilon\rangle$, effective hyperfine field $\left\langle B_{\text {eff }}\right\rangle$, hyperfine field $\left\langle B_{\text {hyp }}\right\rangle$, canting angle $\langle\beta\rangle$ and relative intensity of the sextets $\left\langle I_{\mathrm{rel}}\right\rangle$ for the $\mathrm{CoFe}_{2} \mathrm{O}_{4}$ samples at $12 \mathrm{~K}$ in an external magnetic field of $8 \mathrm{~T}$ applied parallel to the direction of $\gamma$-rays.

\begin{tabular}{lccccccc}
\hline $\begin{array}{l}\text { Sample } \\
\text { (grain size in } \mathrm{nm})\end{array}$ & Fe site & $\begin{array}{c}\langle I S\rangle^{*}(\mathrm{~mm} / \mathrm{s}) \\
\pm 0.01\end{array}$ & $\begin{array}{c}\langle 2 \varepsilon\rangle(\mathrm{mm} / \mathrm{s}) \\
\pm 0.02\end{array}$ & $\begin{array}{c}\left\langle B_{\text {eff }}\right\rangle(T) \\
\pm 0.5\end{array}$ & $\begin{array}{c}\left\langle B_{\mathrm{hyp}}\right\rangle(T) \\
\pm 0.5\end{array}$ & $\begin{array}{c}\langle\beta\rangle(\text { degrees }) \\
\pm 5\end{array}$ & $\begin{array}{c}I_{\text {rel }}(\%) \\
\pm 1\end{array}$ \\
\hline $\begin{array}{l}\text { As-prepared } \\
\text { (8 nm) }\end{array}$ & $A$ & 0.34 & -0.00 & 59.8 & 52.3 & 20 & 36 \\
Annealed at & $B$ & 0.49 & -0.02 & 46.7 & 53.9 & 29 & 64 \\
$1473 / 2 \mathrm{~h}(92 \mathrm{~nm})$ & $A$ & 0.34 & 0.01 & 60.3 & 52.7 & 17 & 42 \\
\hline
\end{tabular}

*with respect to $\alpha$-Fe at $300 \mathrm{~K}$.

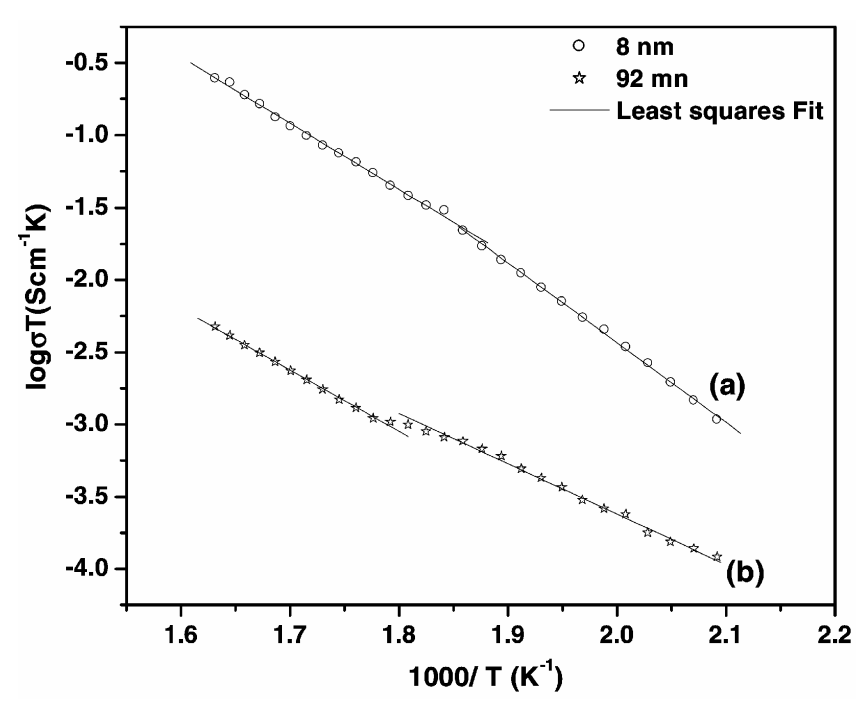

Figure 10. Arrhenius plots for the electrical conductivity of nanocrystalline $\mathrm{CoFe}_{2} \mathrm{O}_{4}$ spinel ferrite for (a) as-prepared $(8 \mathrm{~nm})$ and (b) annealed at $1473 \mathrm{~K}$ for $2 \mathrm{~h}(92 \mathrm{~nm})$ samples. The solid lines are the least-squares fit to $(1)(\mathrm{g}$, grain and $\mathrm{gb}$, grain boundary).

samples. We attribute the increase in $\tan \delta$ from the asprepared to $25 \mathrm{~h}$ milled sample due to oxygen vacancy upon milling. The $\mathrm{Zn}^{2+}$ ions, because of the volatile nature of zinc, are known to escape from the spinel structure on thermal treatment at high temperature or upon mechanical milling in a high energy ball mill (Goya and Rechenberg 1999). Therefore, in the present study, it is possible that the number of $\mathrm{Zn}^{2+}$ ions that escape from the spinel structure increases with milling, which results in oxygen vacancies and hence higher dielectric losses as observed for the $25 \mathrm{~h}$ milled sample.

(ii) Temperature dependence of $\varepsilon^{\prime}$ and $\tan \delta$ : Figures 7 (a) and (b) show the temperature dependence of $\varepsilon^{\prime}$ and $\tan \delta$ for the as-prepared and $25 \mathrm{~h}$ milled sample, respectively. The dielectric constant and dielectric loss increase with temperature for both the samples, which is normally an expected behaviour and observed in most of the ferrites (Hiti 1968; Ponpandian and Narayanasamy 2002;
Ponpandian et al 2002). The hopping of charge carriers is thermally activated with the temperature rise and hence the dielectric polarization increases causing an increase in $\varepsilon^{\prime}$ and $\tan \delta$ with temperature.

\section{$3.2 \mathrm{CoFe}_{2} \mathrm{O}_{4}$}

3.2a Phase analysis: Figure 8 shows the XRD patterns of the as-prepared sample (A) and the sample annealed at $1473 \mathrm{~K} / 2 \mathrm{~h}$ (B). The two patterns in figure 8 could be indexed to single spinel phase. The average grain sizes were calculated using Scherrer's formula taking into account the instrumental line broadening. The average grain sizes of samples A and B were 8 and $92 \mathrm{~nm}$, respectively.

3.2b In-field Mössbauer studies: To find the changes in the cation distribution of $\mathrm{CoFe}_{2} \mathrm{O}_{4}$ with heat treatment, we have recorded the in-field ${ }^{57} \mathrm{Fe}$ Mössbauer spectra for both $A$ and $B$ samples which are shown in figure 9. The Mössbauer spectra were fitted with two magnetic components arising from the tetrahedral $(A)$ and octahedral $(B)$ sites of $\mathrm{Fe}^{3+}$ ions. The experimental data have been fitted by using the least-squares MOSFIT program (Teillet and Varret). The refined values of hyperfine parameters are listed in table 2 . The sextet with the smaller value of isomer shift of $0.34 \mathrm{~mm} / \mathrm{s}$ is unambiguously assigned to the tetrahedral $\mathrm{Fe}^{3+}$ ions, and the other one to the octahedral $\mathrm{Fe}^{3+}$ ions. The relative intensities of the $A$-site and $B$-site sextets obtained from the fitting of the in-field Mössbauer spectra are reliable as the spectra of the two sites are now well resolved. The ratio of intensity of the $A$-site sextet to that of the $B$-site sextet is expected to be 1 , which is the ratio of the population of the $\mathrm{Fe}^{3+}$ ions in $A$ sites to that in $B$ sites, provided $\mathrm{Co}^{2+}$ ions are only in the $B$ sites as observed in bulk sized particles. But the experimental values obtained from the intensities of the $A$ - and $B$-site sextets are 0.56 and 0.72 for samples with 8 and $92 \mathrm{~nm}$ grain sizes, respectively. It is possible only if some of the $\mathrm{Fe}^{3+}$ ions from the octahedral sites migrate to the tetrahedral sites on thermal annealing at $1473 \mathrm{~K}$ for $2 \mathrm{~h}$.

3.2c D.C. conductivity: Figure 10 shows the Arrhenius plots for the electrical conductivity of the as-prepared and 
heat treated samples, plotted in the temperature range from $475-625 \mathrm{~K}$. For the two samples there is a change in the slope of the straight lines at about a temperature of $540 \pm 3 \mathrm{~K}$, which is much below their Néel temperatures. Figure 10 shows that the conductivity decreases when the grain size increases from $8-92 \mathrm{~nm}$ whereas it is expected to increase with the grain size. The possible change in cation distribution on annealing at $1473 \mathrm{~K}$ for $2 \mathrm{~h}$ might have contributed to the observed decrease in the conductivity. The in-field Mössbauer gave a clear evidence for the migration of some of the $\mathrm{Fe}^{3+}$ ions from the octahedral to tetrahedral sites as discussed in detail in $\$ 3.2 \mathrm{~b}$. In cobalt ferrites, the hopping of both electrons and holes contributes to the electrical conductivity. The decrease in the number
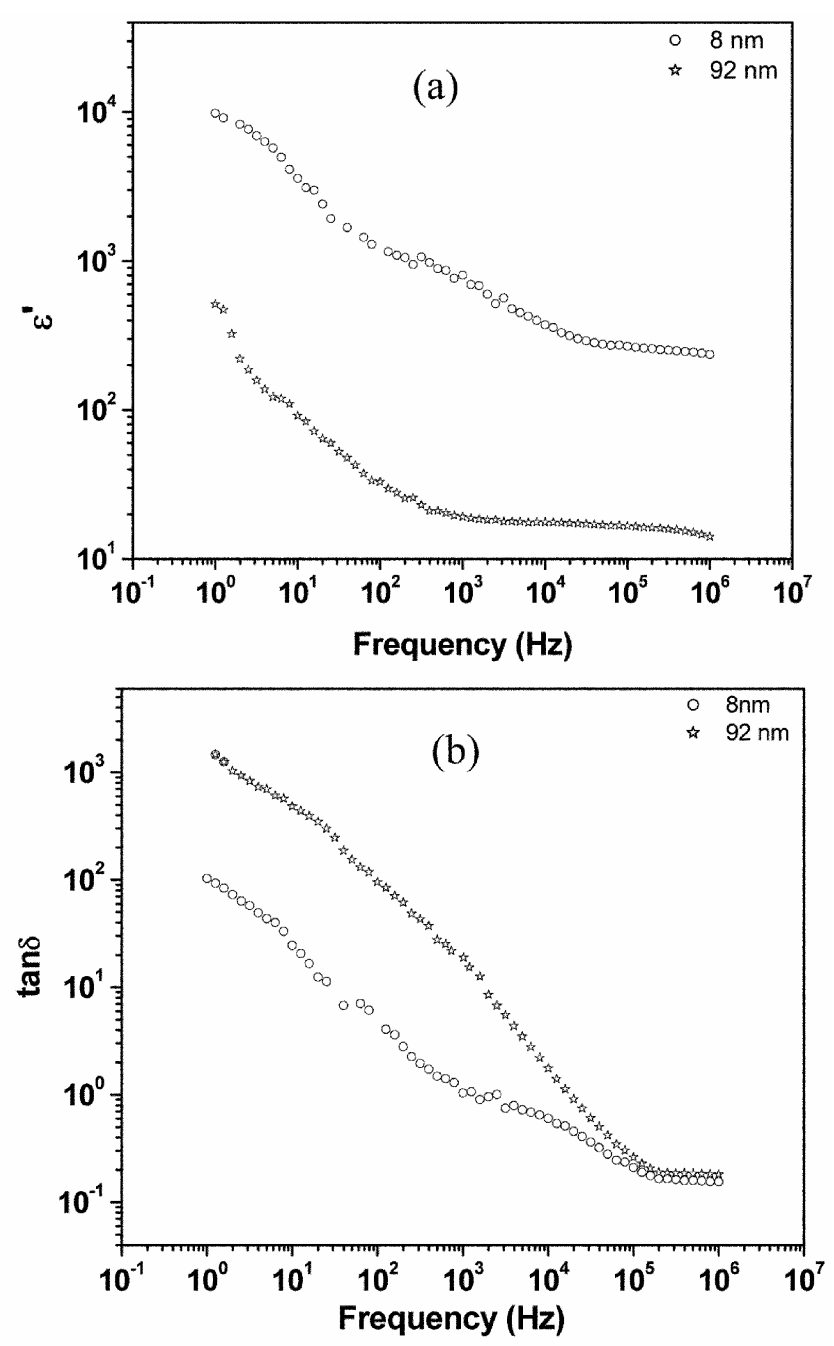

Figure 11. (a) Real part of the dielectric constant $\left(\varepsilon^{\prime}\right)$ at $473 \mathrm{~K}$ as a function of frequency for as-prepared $(8 \mathrm{~nm})$ $\mathrm{CoFe}_{2} \mathrm{O}_{4}$ sample and sample annealed at $1473 \mathrm{~K}$ for $2 \mathrm{~h}(92 \mathrm{~nm})$ and (b) dielectric loss factor $(\tan \delta$ ) at $473 \mathrm{~K}$ as a function of frequency for as-prepared $(8 \mathrm{~nm}) \mathrm{CoFe}_{2} \mathrm{O}_{4}$ sample and sample annealed at $1473 \mathrm{~K}$ for $2 \mathrm{~h}(92 \mathrm{~nm})$. of iron ions in octahedral site will result in the decrease of $\mathrm{Fe}^{2+} \leftrightarrow \mathrm{Fe}^{3+}$ pairs contributing to the decrease in conductivity.

$3.2 \mathrm{~d}$ Variation of $\varepsilon^{\prime}$ and $\tan \delta$ with frequency: Figure 11(a) shows the effect of frequency on the real part of the dielectric constant $\varepsilon^{\prime}$ at $473 \mathrm{~K}$ for both $\mathrm{A}$ and B samples. Mahajan et al (2002) observed that the real part, $\varepsilon^{\prime}$, of the dielectric constant is of the order of $10^{2}$ at $473 \mathrm{~K}$ at a frequency of $1 \mathrm{kHz}$ for the bulk cobalt ferrite. In the present work, the real part of the dielectric constant for sample A is of the order of $10^{3}$ at $473 \mathrm{~K}$ at a frequency of $1 \mathrm{kHz}$. The dielectric constant is found to be an order of magnitude higher for the $8 \mathrm{~nm}$ particles compared to that of the bulk cobalt ferrite (Mahajan et al 2002). The high dielectric constant for $8 \mathrm{~nm} \mathrm{CoFe} \mathrm{O}_{4}$ particles, therefore, makes them suitable for microwave applications. Moreover, the dielectric constant decreases by more than an order of magnitude when the grain size increases from 8-92 nm. This is due to the reduction of $\mathrm{Fe}^{2+} \leftrightarrow \mathrm{Fe}^{3+}$ pairs in $B$ sites as a consequence of the decrease in the number of iron ions in $B$-sites, as revealed by the in-field Mössbauer studies as discussed in detail in $\$ 3.2 \mathrm{~b}$.

The plots between dielectric loss $(\tan \delta$ ) and frequency for samples A and B are shown in figure 11(b). Shitre et al (2002) observed that $\tan \delta$ is around 0.4 at $300 \mathrm{~K}$ in the frequency range of $1 \mathrm{kHz}$ for the bulk cobalt ferrite prepared by ceramic method. In the present study, $\tan \delta$ for sample A $(8 \mathrm{~nm})$ is about 0.0325 at $300 \mathrm{~K}$ in the same frequency range. The dielectric loss is thus found to be an order of magnitude lower for the $8 \mathrm{~nm}$ particles compared to that of the bulk cobalt ferrite (Shitre et al 2002). The sample A $(8 \mathrm{~nm})$ can, therefore, be used for high frequency communication because of the low value of dielectric loss.

\section{Conclusions}

In the case of $\mathrm{Ni}_{0.5} \mathrm{Zn}_{0.5} \mathrm{Fe}_{2} \mathrm{O}_{4}$, the Néel temperature is found to be enhanced to $611 \mathrm{~K}$ for the $25 \mathrm{~h}$ milled sample which is attributed to the increase in the superexchange interaction strength resulting from the migration of $\mathrm{Fe}^{3+}$ ions from the octahedral to tetrahedral sites upon milling. The oxygen vacancies created upon milling increase the conductivity. The dielectric constant for the $25 \mathrm{~h}$ milled sample is smaller by an order of magnitude and the dielectric loss is three orders of magnitude smaller compared to that of the bulk. The anomalous frequency dependence of the dielectric constant arises from the two types of charge carriers present in this ferrite. In $\mathrm{CoFe}_{2} \mathrm{O}_{4}$, we conclude that the electrical conductivity and the dielectric properties could be tailor made by controlling cation distribution through thermal annealing. The dielectric loss is found to be smaller for the nanometer sized particles. 


\section{Acknowledgements}

We acknowledge Dr J-M Greneche for the in-field Mössbauer measurements, Dr K Shinoda and Dr B Jeyadevan for EXAFS experiments, Dr C N Chinnasamy for supplying the as-prepared cobalt ferrite sample and Dr N Ponpandian and Dr G Govindaraj for fruitful discussions. The financial support from DST, Government of India (Sanction No.SR/S5/NM-23/2002) is also acknowledged.

\section{References}

Abdeen A M 1999 J. Magn. Magn. Mater. 192121

Bulte J W M, Cuyper M de, Despres D and Frank J A 1999 J. Magn. Magn. Mater. 194204

Goya G F and Rechenberg H R 1999 J. Magn. Magn. Mater. 203141

Hiti M A 1968 J. Magn. Magn. Mater. 164231

Igarash H and Okazaki K 1977 J. Am. Ceram. Soc. 6051

Irvine J T S, Huanosta A, Velenzuela R and West A R $1990 \mathrm{~J}$. Am. Ceram. Soc. 73729
Koops C G 1951 Phys. Rev. 83121

Kulikowski J 1984 J. Magn. Magn. Mater. 4156

Lübbe A S, Bergemann C, Brock J and McClure D G $1999 \mathrm{~J}$. Magn. Magn. Mater. 194149

Mahajan P R, Patankar K K, Kothale M B, Chaudhari S C, Mathe V L and Patil S A 2002 Pramana-J. Phys. 581115

Ponpandian N and Narayanasamy A 2002 J. Appl. Phys. 92 2770

Ponpandian N, Balaya P and Narayanasamy A 2002 J. Phys.: Condens. Matter 143221

Rezlescu N and Rezlescu E 1974 Phys. Status Solidi (a) 23575

Shitre A R, Kawade V B, Bichile G K and Jadhav K M 2002 Mater. Lett. 56188

Sivakumar N, Narayanasamy A, Ponpandian N, Greneche J M, Shinoda K, Jeyadevan B and Tohji K 2006 J. Phys. D: Appl. Phys. 394688

Smit J and Wijn H P J 1959 Ferrites (Eindhovan: Philips) p. 158

Teillet J and Varret F MOSFIT program, Université du Maine, Le Mans, France (unpublished)

Verma A, Goel T C, Mendiratta R G and Alam M I 1999 Mater. Sci. Eng. B60 156

Waster R 1991 J. Am. Ceram. Soc. 741934 